tous redness of the sound mucous membrane seemed to follow the use of the carbid, which would suggest that it resulted from an escharotic action of the acetylene gas. Whether the acetylene gas destroys the cancer cell by annihilative action, or by chemically changing it, remains to be seen. One thing seems to be certain, and that is that the carbid of calcium at least postpones death and makes carcinoma patients vastly more comfortable while they do live, than any treatment known to the writer.

31 Washington St.

\section{CHRONIC PHLEBITIS OF THE SAPHENOUS VEINS; SAPHENECTOMY.}

BY E. VIKO, M.D.

PARK CITY, UTAH.

The pathologic condition of chronic phlebitis is a sclerosis of the veins, similar to atheromatous changes in the arteries; the veins become cord-like All the coats of the veins may be thickened and indurated, or the external coat only may be affected. In chronic phlebitis of the saphenous veins of the leg, the tissues around the veins are also swollen, often several times their natural size. Varices of the adjacent branches sometimes occur. In cases of long standing, eczema and ulcerated patches affect the skin, which becomes hard, thick and glazed. Severe pain, especially on standing or walking, is complained of.

Medicinal treatment of chronic phlebitis of the saphenous veins is very unsatisfactory. Drugs may ameliorate the eczema, pain and swelling to a certain extent, but this is only temporary.

Surgery promises better results. Lea recommends tying of the veins. The most rational method seems to be the removal of the veins. They have lost their function and act only as an irritant. No surgery to which I have access recommends removal of the saphe. nous veins for chronic phlebitis; but in view of the fact that their removal for varices effects the surest and speediest cure, I decided in one case to remove the internal saphenous vein for chronic phlebitis, with the happiest results.

Mrs. F., age 55 years, had been suffering for fourteen years with chronic phlebitis of the internal saphenous vein of the left leg. The limb was greatly swollen and walking or standing occasioned severe pains A good part of the time she could not obtain the necessary sleep on account of the pain. The skin of the log was covered with an intractable eczema. She had for several years used a variety of drugs, internally and externally, with very little result. I suggested the removal of the vein, and on Feb. 28, 1898, I cut down on the vein in front of the internal malleolus; it was considered easier to find the vein there than higher up on account of the swelling. The vein felt and looked like a tendon. The only way by which I could tell whether it was the vein or not was by pricking it. The tissues over the vein were then laid open to about an inch above the knee, where the vein seemed to be healthy. The swollen and indurated tissues over the vein were in most places about an inch and a half in thickness. The vein was tied in two places above the knee with No. 2 formalinized catgut and was severed between the ligatures. As the vein was dissected out downward, branches were tied with the same material. It was finally tied near the internal malleolus and removed. I was careful not to injure the internal saphenous nerve. The wound was closed with No. 2 formalinized catgut and dressed with aseptic gauze and cotton. There was no rise of temperature at any time except on the second day, when the thermometer registered 99.5 degrees. The wound healed by primary union. All the swelling, induration and eczema have left the leg and she is now free from pain, the first time in fourteen years. Walking or standing does not cause any pain or swelling in the limb.

I have examined several surgical works, even of recent date, and find no mention of removal of the internal saphenous vein for chronic phlebitis.

These cases are frequently met with and the old treatment recommended is anything but satisfactory, while saphenectomy seems to be a sure and speedy remedy.

In my experience in varices of the internal saphenous vein removal is better than Phelps' operation.

\section{SOCIETY PROCEEDINGS.}

\section{Delaware State Medical Society.}

\author{
Meeting held in Wilmington, Del., June 14, 1898.
}

The meeting was opened by the President, Dr. P. W. TomLINSON of Wilmington, who delivered an address entitled,

THE INTERESTS, OBJECTS AND BUSINESS OF OUR SOCIETY.

After commenting on the fact that the charter of this Society was only thirteen years younger than the Declaration of Independence he referred to some of the reasons why medical men did not take more interest in their annual medical meetings. $\mathrm{He}$ urged all to make known by writing and talking whatever new observations they may make of interest to medical men and considered a medical society the best means of conveyance for this information. He then dwelt at great length on the purposes of State medical societies in general and quoted fully from a number of letters received from other States, as to the results obtained by these societies in elevating the profession and killing quackery.

Dr. Willard SPRINGer read a paper entitled SHORT HISTORY OF 1800 OBSTETRIC CASES.

The author divided this subject into eighteen groups of 100 each and mentioned one or two interesting cases in each group. $\mathrm{He}$ said concerning his management of cases : "If the case is an ordinary one and the labor well advanced and likely to be over soon after I first see it, I use the ordinary precaution of thoroughly washing my hands in hot water, but if the case is likely to be prolonged and to require many digital examinations or perhaps operative interference I use a bichlorid solution for my hands, carbolized vaselin as a lubricant and a solution of creolin for my instruments. Of course I occasionally have a case of septic infection and then, when the temperature is high and the lochia offensive, I use an intra-uterine douche of a mild bichlorid solution, 1 to 4000 . Last winter I saw a case in another physician's practice in which the temperature was above 106 degrees just before the douche was given. The next morning it was down to 103 degrees and never went so high again, but the woman made a slow recovery on account of an attack of puerperal mania. I have great confldence in antiseptic and aseptic precautions in operations of all kinds, but I do not see that I have any fewer deaths in my obstetric practice now than I did in the early years when such precautions were unknown.

Dr. John PaLmer of Wilmington, gave the details of a case briefly referred to by Dr. Springer, in which the instruments were applied for five or six hours and the brain of the child squeezed out of the head before it was delivered, the mother making a good recovery.

Dr. Joskphine White asked how often Dr. Springer had administered anesthetics in the first stage of labor in his 1800 cases and in how many cases the temperature went above nor. $\mathrm{mal}$. She also commented on the indifference displayed by the better and upper middle classes toward absolute cleanliness in obstetric work and did not believe that the possibility of postpartem hemorrhage was a contra-indication to the administration of an anesthetic.

Dr. W. H. HANCKER of Farnhurst, Del., detailed a case of delirium following septicemia in which the emptying of the uterus was followed by death in two days. 